Aleksandar Štulhofer ${ }^{\mathrm{a}}$
Vatroslav Jelovica
Jan Ružić

\title{
Is Early Exposure to Pornography a Risk Factor for Sexual Compulsivity? Findings from an Online Survey among Young Heterosexual Adults
}

Running head: Early exposure to pornography and sexual compulsivity

Address for correspondence:

\author{
Aleksandar Štulhofer, $\mathrm{PhD}$ \\ Sexology Unit, Dept of Sociology \\ Faculty of Humanities and Social Sciences \\ University of Zagreb \\ I. Lučića 3, 10000 Zagreb, Croatia \\ Fax: +38516157869 \\ E-mail: astulhof@ffzg.hr
}


Abstract: The aim of this retrospective study was to assess the relationship between early exposure to pornography and sexual compulsivity among Croatian young adults. Using online survey data on pornography use and sexual behavior among 1528 heterosexual women and men aged 18-25, we tested a hypothesis that pornography use at the age of 14 is a marker for sexual compulsivity in late adolescence and young adulthood. After satisfactory reliability of a 4-item subscale of the Sexual Compulsiveness Scale (Kalichman \& Rompa, 1995) was confirmed in this sample, construct validity of this composite indicator focused on out of control sexual thoughts and behaviors was assessed. High sexual compulsivity was associated with sexual risk taking, though mainly among women, decreased levels of relationship intimacy and lesser sexual contentment. However, we found no significant association between early exposure to pornography and high sexual compulsivity either among men or women.

Key Words: pornography, sexual compulsivity, risk taking, intimacy, sexual satisfaction

\section{Introduction}

Sexual Compulsivity (SC) is a clinical phenomenon characterized by sexual urges, fantasies and behaviors that are sufficiently recurrent and intense as to interfere with one's normal daily functioning (Miner et al., 2006; Parsons et al., 2007). Terms sexual addiction and compulsive sexual behavior have also been used for this condition (Coleman, 1986). Compulsive masturbation, excessive use of pornography and online sexual chat and dating services, sex with multiple and often anonymous partners, and obsessive sexual thoughts are usually reported as symptoms of SC (Parsons et al., 2007). Individuals with SC often recognize that their sexual behavior is excessive and often disruptive, both personally and socially, but they claim to be unable to control it (Miner et al., 2006:1). Clinical studies provide evidence of 
comorbidity with anxiety disorders, depression, eating disorders and substance abuse (Bancroft \& Vukadinovic, 2005; Black, Kehrlberg, Flumerfelt, \& Schlosser, 1997; Kafka \& Prentky, 1994; Schwartz \& Southern, 2000). Compulsive sexual behavior may cause a myriad of personal problems, ranging from relationship difficulties to problems with the law. It also carries increased health risks, such as exposure to HIV infection and other sexually transmitted diseases (Dodge, 2004; Miner et al., 2006).

Although no consensus exists at the moment whether SC should be conceptualized as a subtype of obsessive-compulsive disorder (Coleman, 1992; Kaplan, 1996), an addiction (Carnes, 1992), or a kind of self-regulatory or behavioral control disorder (Bancroft \& Vukadinovic, 2005), many researchers and therapists consider it a useful clinical category (Griffiths, 2001). In spite of a noticeable increase in attention paid to this controversial phenomenon, the available literature has been more preoccupied with defining the condition than with exploring its etiology (Bancroft \& Vukadinovic, 2005; Parsons et al., 2007).

The link between pornography and SC has been suggested or implied by a number of researchers and clinicians (Carnes, 1992; Cooper et al., 2000, 2004; Griffiths, 2001; Schwartz \& Southern, 2000). Although excessive use of sexually explicit materials has been explored as a symptom or a trigger for obsessive sexual behaviors, there is a lack of research into pornography exposure as a possible risk factor for developing SC. Could early exposure to pornography predict SC? We are not suggesting a simple causal effect: exposure to pornography, particularly at a younger age, could function as a trigger for a set of thoughts and behaviors that could activate (or facilitate the activation of) individual potential or predisposition for the condition, much like the exposure to violent pornography may facilitate sexually aggressive behavior in men who are prone to hostile masculinity - as pointed out in the Confluence Model of sexual aggression (Bogaert, 2001; Malamuth, Addison \& Koss, 2000; Malamuth \& Huppin, 2005). By presenting sex as readily available and possible in all 
situations, by depicting actors as insatiable and almost obsessed with sexual fulfillment, pornography could reduce inhibitions, facilitating the development of elaborate sexual fantasies and extensive erotic daydreaming. This could particularly be the case when SC is associated with paraphilic preferences. Paraphilic contents, readily available on the Internet (Cooper et al., 2004; Delmonico et al., 2002; Griffiths, 2001), could not only create an impression that these practices are more common than they really are, but could also "normalize" a person's view of his/her sexual fantasies, justifying a rising preoccupation with sexual thoughts and behaviors.

In this paper, we test the hypothesis that early exposure to pornography is a risk factor for SC in a sample of young Croatian adults aged 18-25. After assessing its reliability, we analyze construct validity of a subset of the Sexual Compulsivity Scale (Kalichman \& Rompa, 1995) through the relationship with three negative outcomes associated with SCsexual risk taking, lesser relationship intimacy, and sexual dissatisfaction (Benotsch et al., 1999; Bergner \& Bridges, 2002; Carnes, 1992; Cooper et al., 2000; Dodge et al., 2004; Kalichman \& Cain, 2004; Leiblum, 1997; Parsons et al., 2007). Finally, we test the relationship between SC and early exposure to pornography (14 or younger) and frequency of its use at 14 , while controlling for the currently preferred pornographic genre. ${ }^{1}$

\section{Method}

\section{Procedure and Participants}

An online survey on pornography use among young adults was carried out at the end of 2006 (Štulhofer et al., 2007). Participation was solicited via a generic e-mail message that was sent to college students' mailing lists at several Croatian universities and a number of electronic forums. The message contained a brief explanation of the research study, the link to online questionnaire and a request which asked the recipient to forward the message to their friends

\footnotetext{
${ }^{1}$ In Croatia, most young people finish their primary schooling at the age of 14 . This marks the end of a distinct and psychosocially important period, which should facilitate recollections about that age/period. Also, age 14 is the legal age of consent and legal culpability in Croatia.
} 
and acquaintances aged 18-25. Of 4,605 participants who started the questionnaire, 3,136 completed the task ( $68 \%$ completion rate). After excluding participants of ineligible age (under 18 and over 25), those who did not provide information about their age or sex, those whose answers contained over $10 \%$ of missing values, those who did not use pornography at any of the time points retrospectively assessed (at the age of 14, at the age of 17 and in the last 12 months), those who did not report sexual intercourse, and those who reported having at least one sexual partner of the same $\operatorname{sex}^{2}$, the sample was reduced to 1,528 participants (mean age $=22 ; \mathrm{SD}=2.02)$ :The majority of participants were living in a large urban setting and had parents with above average education (Štulhofer et al., 2007).

The study was approved by the Ethical Review Board for the Protection of Human Subjects at the Faculty of Humanities and Social Sciences, University of Zagreb, Croatia.

\section{Questionnaire}

The questionnaire application was based on Microsoft ASP.NET version 2 technology. To ensure anonymity and confidentiality, neither IP address recording nor permanent cookies were used. This made multiple submissions possible, but, considering the length of the questionnaire and the fact that no incentives were offered for participation, highly unlikely.

The initial page provided information about the study and participation, and contained a button that needed to be clicked on (confirming consent and age eligibility, 18 or older) for the survey questions to be accessed. The questionnaire consisted of 244 variables divided into sociodemographic, sexual behavior, sex attitudes, exposure to pornography, and attitudes toward pornography sections. Up to 40 minutes were required to complete the questionnaire. In the introductory part, pornography was defined as "direct, detailed, and uncensored depiction of sexual activities that most people refer to as pornography”.

\section{Instruments}

\footnotetext{
${ }^{2}$ Insufficient number of participants reporting same-sex sexual partners focused our analysis exclusively on heterosexual participants.
} 
Sexual compulsiveness was assessed with a subset of Kalichman's Sexual Compulsivity Scale (Kalichman \& Rompa, 1995). The original scale was composed of 10 items asking about the degree of participant's endorsement of a set of sexually compulsive behaviors and thoughts, such as: "My sexual thoughts and behaviors are causing problems in my life" or "My sexual appetite has gotten in the way of my relationships". All items were anchored on a 5-point Likert-type scale ranging from $1=$ "not at all like me" to $5=$ "exactly like me". ${ }^{3}$ As it has been recently pointed out, the SC scale may be measuring a wider construct than originally intended (Dodge et al., 2004). In an attempt to reduce this validity problem, we utilized a subset of the SC scale as the indicator of inability to control one's sexual thoughts and behaviors, which has been identified as the core symptom of SC (Bancroft \& Vukadinovic, 2005; Salisbury, 2008). The four chosen variables ("My sexual thoughts and behaviors are causing problems in my life", "My desires to have sex have disrupted my daily life", "I sometimes fail to meet my commitments and responsibilities because of my sexual behaviors", and "I find that my sexual thoughts and feelings are stronger than me") were found to have satisfactory reliability $(\alpha=.82$.), only slightly lower than the original 10 -item scale $(\alpha=.86)$.

Three variables were used as indicators of exposure to pornography: age at first exposure to pornography, frequency of use at the age of $14(1=$ never, $2=$ once a month or less, $3=$ several times a month, $4=$ several times a week, $5=$ every day), and preferred pornographic genre. Age at first exposure was dichotomized into "14 or younger" (1) and "15 or older" (0). Pornographic genre was a dichotomous variable based on four yes/no format questions regarding preferred ("most often sought") sexually explicit contents. The four listed genres were: $S \& M / B \& D$, fetishism, bestiality, and violent/coercive sexual activities. Participants who reported preference for at least one of the four types (multiple choice was

\footnotetext{
${ }^{3}$ The original measure has a 4-point answering scale.
} 
possible) were defined as users of paraphilic pornography (1). The others were placed in the mainstream pornography user group (0).

Sexual risk taking was assessed by three one-item indicators: condom used at last sexual intercourse (yes/no), consistent use of condoms during the preceding month (yes/no), and number of sexual partners in the last year. The choice of sexual risk taking indicators was guided primarily by HIV/AIDS literature (Slaymaker, 2004; Wellings et al., 2006).

Sexual intimacy was measured by the degree of intimacy in current relationship (or, if currently not in relationship, in the most recent one), partner communication about sexuality, and attitudes toward committed relationships. Intimacy was assessed by five items based on the Miller Social Intimacy Scale (Miller \& Lefcourt, 1982). The items measured the degree to which one feels close to their partner, readiness to help the partner when he/she has problems or feels low, the need to open up emotionally to one's partner, to share highly personal information, and to spend time together. Responses were given on a 5 -point scale $(1=$ almost never to $5=$ almost always), with higher composite scores denoting higher levels of intimacy. The scale had acceptable internal consistency (Cronbach's $\alpha=.79$ ). Communication with one's partner about sexual matters was measured with eight yes/no format items regarding communication about personal and partner's sexual problems, preferences, sexual history, sexual health, and pornography. Scores were aggregated in a scale ranging from 0 (no communication) to 10 (communication about all aspects). The scale had satisfactory reliability $(\alpha=.84)$. Relationship attitudes were assessed by six Likert-type items asking about committed relationship, developed in an earlier Internet study by the first author (Štulhofer et al., 2006). Sample items include: "Love is overrated", "Relationships take away one's freedom", "Sooner or later every relationship deteriorates into a routine", and "It is better to have brief affairs than to be in a relationship". Higher scores represented more negative perception of committed relationships. Cronbach's $\alpha$ for the scale was .82 . 
Sexual contentment was assessed with two composite indicators, sexual satisfaction and sexual boredom, and an indicator of anxiety and guilt related to one's sexual activity. Satisfaction with one's sexual life was measured by the modified Snell's Index of Sexual Satisfaction (Snell et al, 1993). The original instrument was reduced from five to three Likerttype items to include satisfaction with the way in which one's sexual needs are being met, the degree in which on feels sexually fulfilled, and the appraisal of whether something is presently missing in one's sexual life. Higher scores indicated higher level of sexual satisfaction. Cronbach's $\alpha$ for the scale was .92 . Sexual boredom was assessed by a brief version of the 18-item Sexual Boredom Scale (Watt \& Ewing, 1996). Ten items that loaded highly on two dimensions of the scale (Sexual Monotony and Sexual Sensation) were included in the initial version of the questionnaire. After a pre-test the scale was further reduced to five items. Responses were recorded on a 5-point scale (from $1=$ completely disagree to $5=$ completely agree). Higher scores represented increased susceptibility to sexual boredom. Internal consistency of this shortened scale was satisfactory $(\alpha=.88)$. Anxiety and guilt related to one's sexuality was assessed by the following question: "In the last year, how often did you experience anxiety, nervousness or guilt feelings due to something related to your sexual life?" Responses were anchored on a 4-point scale ranging from never (1) to often (4).

\section{Data Analysis}

Data analyses included descriptive and inferential statistical analyses. Gender differences in sociodemographic characteristics and sexual behaviors were assessed using $\chi^{2}$ test. In the next step, construct validity of the 4-item subset of the Sexual Compulsivity Scale in the Croatian sample was tested (the scale was correlated with indicators of sexual risk taking, sexual intimacy, and sexual contentment) using Spearman's rank and point biserial correlation coefficients. Due to differences in sexual socialization and the dominant societal norms 
regulating sexuality and the use of pornography, the analysis was carried out separately for women and men.

Following Benotsch et al. (1999), the 4-item SC scale was then dichotomized, so that participants scoring at the 80th percentile or higher were assigned to the high SC group (1) and those scoring below the 80th percentile were assigned to the low SC group (0). The cutoff point was well above one standard deviation from the mean score. In the final step, multiple logistic regression was used to test multiple associations between high/low SC, early exposure to pornography and frequency of its use, while controlling for age and preferred pornographic genre. Again, the analysis was carried out separately for women and men.

\section{Results}

More than half of participants were living in big urban settings. Participants with college educated parents were overrepresented in the sample (less than $10 \%$ of Croatian population has college diploma). No significant gender differences were observed in age of first sexual intercourse or lifetime number of sexual partners (Table 1). In comparison to men, women reported being first exposed to pornography at slightly older age. On average, the first male exposure occurred at the age of $10(M=10.3, S D=2.64)$ and the first female exposure a year later $(M=11.3, S D=2.99)$. Over one third of women and almost one half of men reported the first contact with pornography at the age of 10 or younger. As expected, there was a significant gender difference in SC. Men scored significantly higher on the 4-item SC scale than women $\left(M_{\text {male }}=8.33, S D=3.29\right.$ and $M_{\text {female }}=6.88, S D=2.71 ; t=8.95, d f=1050.28, p$

$<.001)$. After the scale was dichotomized, men were overrepresented in the high SC group $\left(\chi^{2}\right.$ $=58.16, d f=1, p<.001)$. In total, $14.1 \%$ of women and $30.3 \%$ of men were placed in the high SC group.

\section{TABLE 1 ABOUT HERE!}

\section{Risky Sex and Sexual Compulsivity}


Among women, two of the three indicators of sexual risk taking (condom use consistency and number of sexual partners in the preceding year) were found weakly but significantly associated with SC (Table 2). Among men, only one indicator, number of sexual partners, was found correlated with SC in the expected direction.

\section{Intimacy and Sexual Compulsivity}

Significant association between SC and relationship intimacy, partner communication, and attitudes toward intimate relationships were observed among female participants (Table 2). The higher the SC score, the lower levels of intimacy achieved in present (or previous) relationship, the less frequent communication about sex with one's partner, and the more negative views regarding intimate relationships. Of the three indicators, only partner communication was not found significantly associated with SC among men.

\section{Sexual Contentment and Sexual Compulsivity}

All three indicators of sexual contentment-sexual satisfaction, sexual boredom, and anxiety and guilty feelings after sex-were significantly associated with sexual compulsivity among both men and women (Table 2). All associations were in the expected direction. The higher the SC score, the lesser reported satisfaction with one's sex life, the higher levels of sexual boredom, and the more anxiety and guilty feelings after sexual activities.

\section{TABLE 2 ABOUT HERE!}

Comparable results were obtained when differences between the low and high SC group were tested on the indicators of sexual risk taking, sexual intimacy, and sexual contentment (Table 3). The discrepancy between the correlational and inter-group difference analysis was observed mainly in the female subsample. No statistically significant difference was found between the low and high SC scoring women in condom use consistency, partner communication, and the average Intimacy scale scores. The difference in the lifetime number 
of sexual partners was verging on statistical significance among women and was insignificant among men.

\section{TABLE 3 ABOUT HERE!}

\section{Early Exposure to Pornography and High Sexual Compulsivity}

Among both men and women, individuals in the high SC group reported more intensive current use of pornography — measured by the average number of hours of pornography consumption per week (the variable was categorized; cf. Table 1) - than those in the low SC group $\left(\chi_{\text {male }}^{2}=13.29, d f=4, p<.01 ; \chi_{\text {female }}^{2}=10.02, d f=4, p<.05\right)$. However, as Table 4 shows, age at first contact with sexually explicit materials was not found significantly associated with high SC in either gender. The same was true for frequency of use at 14 . The only significant correlate was the control variable, currently preferred pornographic genre $\left(\mathrm{OR}_{\text {female }}=2.36, p<.001 ; \mathrm{OR}_{\text {male }}=1.74, p<.01\right)$. The inclusion of this variable was based on its significant association with the low vs. high SC membership $\left(\chi_{\text {male }}^{2}=7.87, d f=1, p<.01\right.$; $\left.\chi_{\text {female }}^{2}=21.78, d f=1, p<.001\right)$. Two thirds of women $(49 / 74 ; 66.2 \%)$ and over one half of men $(65 / 105 ; 61.9 \%)$ in the high SC group reported current preference for paraphilic pornography.

\section{TABLE 4 ABOUT HERE!}

\section{Discussion}

The development of digital technology and World Wide Web made pornography ubiquitous (Cooper, Delmonico, \& Burg, 2000; Kanuga \& Rosenfeld, 2004). In the Western world, this omnipresence, embedded in a culture of sexual permissiveness, resulted in normalization of pornography use, evident not only at micro level — in the ease with which young people talk today about pornography and its role in their lives - but also at macro level, as reflected in the porno chic trend (McNair, 2002). These social and cultural dynamics were not met by intensified research interest into potential effects of pornography on sexual socialization, in 
spite of the evidence of substantial increase in young people's exposure to pornography (Kanuga \& Rosenfeld, 2004; Freeman-Longo, 2000; Wolak, Mitchell, \& Finkelhor, 2007; Ybarra \& Mitchell, 2005). Although it has been suggested that early contact with pornography may be detrimental for young people (Flood 2007; Zillmann, 2000), there is no solid evidence to corroborate such assumptions. It has been shown that more pornography exposure may lead to greater perceived reality of sexually explicit materials, which, in turn, affects attitudes toward recreational sex (Peter \& Valkenburg, 2006). Also, a recent study implicated a negative impact of cumulative pornography exposure (starting at the age of 14) on relationship intimacy among young men (Štulhofer et al., 2007). However, apart from clinical impressions, very little data on the relationship between pornography use and SC is available (Cooper et al, 2000; 2004).

In this paper, we tested a hypothesis that early exposure to pornography may contribute to SC in young adulthood. Our approach to measuring SC started from the Sexual Compulsivity Scale (Kalichman \& Rompa, 2005). This often used instrument for assessing $\mathrm{SC}$ was developed by adapting items from a self-help guide for individuals with out of control sexual urges and behaviors (Carnes, 1992). The scale items were described by the authors as reflecting "obsessive preoccupations with sexual acts and encounters" and "a rigid pattern of sexual behavior with preoccupations and obsessive desires that are resistant to change" (Kalichman \& Rompa, 1995: 588; 595). Although the scale was found to have satisfactory reliability and validity and various samples, an important limitation was recently suggested by Dodge and associates who suggested that it is not only the obsessive and out of control sexual thoughts and behaviors that the SC scale assesses (Dodge et al., 2004). Discussing the findings from a US student sample, they argued that the scale also taps into other constructs, primarily sexual desire and youthful preoccupation with sex, sexual exploration, and sexual novelties. 
In order to minimize this validity problem, we utilized a 4-item subset of the Sexual Compulsivity Scale to measure SC in an online sample of young Croatian adults. The subscale was found consistently correlated with the indicators of sexual intimacy and sexual contentment among both women and men. Partially confirming earlier findings (Dodge et al, 2004; Kalichman \& Cain, 2004; Kalichman \& Rompa, 1995), the subscale was associated with sexual risk taking, but inconsistently-especially among men.

Male participants in the high SC group reported significantly lower levels of intimacy and less positive attitudes toward committed relationship than those in the low SC group. This finding supports the standard clinical emphasis on helping clients with out-of-control sexual behavior to develop capacity for intimate connection and meaningful personal relationships which is often viewed as a crucial step in maintaining emotional (and, consequently, behavioral) self-regulation (Salisbury, 2008). Differences in sexual contentment were the most robust and systematic characteristic dividing participants in the low vs. high SC group. Those in the high SC group were less sexually satisfied and more prone to sexual boredom (men only) and sex-related guilt/anxiety. Again, the finding seems to corroborate clinical insights about the complex negative cycle - beginning and ending with an apparent inability to self-regulate negative affects - that is characteristic of SC (Goodman, 2001; Carnes, 1992).

Our central hypothesis regarding pornography as a risk factor for SC was not confirmed. Neither the age at first exposure, nor frequency of use of sexually explicit materials at the age of 14 differentiated significantly between participants with high/low SC in our sample, regardless of their gender. Although the fact that the preference for paraphilic pornography was found associated with high SC is hardly surprising, interpreting this link requires caution. We had no information regarding the beginning of interest for paraphilic pornography. It is possible that the paraphilic porn preference is an outcome of high SC (due to, for example, excitatory habituation), rather than a risk factor for its development. Another 
mechanism was recently suggested by the confluence model (Malamuth \& Huppin, 2005; Bogaert, 2001), which pointed out that certain personal characteristics (high SC?) may predispose one to search for non-standard pornography.

Although the findings that do not confirm initial hypotheses are substantially less often reported in scholarly journals than those that provide support for theoretically expected relationships, we find the lack of association between early exposure to pornography and later SC noteworthy—especially if frequent warnings about multiple risks of pornography consumption among adolescents and young adults are taken into account (Flood, 2004; Kanuga \& Rosenfeld, 2004; Zillmann, 2000). Certainly, cross-sectional and retrospective design of our study, which, to our knowledge, represents the first attempt to analyze the association between SC and early use of sexually explicit materials, prevents us from making any causal inferences, but its main finding may have some relevance for the future analyses of the effects of pornography exposure among young people.

\section{Study limitations}

Our non-probabilistic sample does not allow ascertaining how well (or badly) it represents either the Croatian online community, or the surveyed age cohort. Clearly, this precludes any generalizations. Moreover, the sample was probably biased by self-selection, resulting in over-representation of sexually permissive individuals (Wiederman, 1999). The fact that reported parents' education was well above national average, lends some support to this assumption.

Another limitation was the exclusion of participants who had no experience with pornography. Since our study was advertised as focusing on young people's experiences with pornography, only seven male participants reported no experience with sexually explicit materials. In our view, this lack of "controls" would constitute a more substantial problem if 
our findings had demonstrated that early use of pornography affected SC scores - which was not the case.

Although we attempted to minimize the problem by limiting participants' age to 25 , it is likely that recall bias was introduced in the study when asking about the early exposure to pornography. Keeping in mind gender-specific differences in exposure to pornography, it is plausible that recall bias did not affect female and male reports equally. Finally, all the measures used in the study relied on self-report, which is a standard limitation in researching sexual behavior.

\section{Conclusions}

We found no statistically significant developmental effect of the early use of pornography operationalized here as the exposure to sexually explicit materials at the age of $14-$ on low levels of (self-reported) control over one's sexual thoughts and behaviors. Although not without shortcomings, this study suggests that the often discussed association between pornography and SC should not be causally interpreted, at least not by imputing causality to the use of pornography. In future studies, methodological approach to the hypothesis tested in this paper could be greatly improved by assessing the conditions and types of early exposure to pornography (willing vs. unwilling initiation; pornography was actively sought after vs. accidentally discovered; use of pornography was personally motivated vs. suggested/insisted upon by someone else, etc.). This would enable more precise and better controlled analyses that may assist in reducing the moral panic attached to pornography use among young people, but also help to improve critical "reading" of the contemporary (pop-cultural) glorification of pornography. 


\section{References}

Bancroft, J., \& Vukadinovic, Z. (2004). Sexual addiction, sexual compulsivity, sexual impulsivity, or what? Toward a theoretical model. Journal of Sex Research, 41, 225234.

Bogaert, A. (2001). Personality, individual differences, and preferences for the sexual media. Archives of Sexual Behavior, 30, 29-53.

Benotsch, E. G., Kalichman, S. C., \& Kelly, J. A. (1999). Sexual compulsivity and substance use in hiv-seropositive men who have sex with men, Prevalence and predictors of highrisk behaviors. Addictive behaviors, 24, 857-868.

Bergner, R. M., \& Bridges, A. (2002). The significance of heavy pornography involvement for romantic partners, Research and clinical implications. Journal of Sex and Marital Therapy, 28, 193-206.

Black, D. W., Kehrberg, L. D., Flumerfelt, D. L., \& Schlosser, S. S. (1997), Characteristics of 36 subjects reporting compulsive sexual behavior. American Journal of Psychiatry, 154, 243-249.

Carnes, P. (1992) Out of the shadows, Understanding sexual addiction. Minneapolis: CompCare.

Coleman, E. (1986). Sexual compulsion vs. sexual addiction: The debate continues. SIECUS Report, July Issue, 7-17.

Coleman, E. (1992). Is your patient suffering from compulsive sexual behavior? Psychiatric Annals, 22, 320-325.

Cooper, A., Delmonico, D. L. \& Burg, R. (2000). Cybersex users, abusers, and compulsives, New findings and implications. Sexual Addiction and Compulsivity, 7, 5-29. 
Cooper, A., Delmonico, D, Griffin-Shelley, E, \& Mathy, R. (2004). Online sexual activity, An examination of potentially problematic behaviors. Sexual Addiction and Compulsivity, 11, 129-144.

Delmonico, D. L., Griffin, E., \& Carnes, P. J. (2002). Treating online sexual compulsive sexual behavior, When cybersex is the drug of choice. In: A. Cooper /Ed./ Sex and the Internet, A Guidebook for Clinicians (pp. 147-167). New York: Brunner-Routledge.

Dodge, B., Reece, M., Cole, S. L., \& Sandfort, T. G. M. (2004). Sexual compulsivity among heterosexual college students. Journal of Sex Research, 41, 343-350.

Flood, M. (2007). Exposure to pornography among youth in Australia. Journal of Sociology, $43,45-60$.

Freeman-Longo, R. E. (2000). Children, teens, and sex on the Internet. Sexual Addiction \& Compulsivity, 7, 75-90.

Goodman, A. (2001). What's in a name? Terminology for designating a syndrome of driven sexual behavior. Sexual Addiction \& Compulsivity, 8, 191-213.

Griffiths, M. (2001). Sex on the Internet, Observations and implications for Internet sex addiction. Journal of Sex Research, 38, 333-342.

Hald, G. M. (2006). Gender differences in pornography consumption among young heterosexual Danish Adults. Archives of Sexual Behavior, 35: 577-585.

Kafka, M. P., \& Prentkym R. A. (1994). Preliminary observations of DSM-III-R Axis I comorbidity in men with paraphilias and paraphilia-related disorders. Journal of Clinical Psychiatry, 55, 481-487.

Kalichman, S. C., \& Rompa, D. (1995). Sexual Sensation Seeking and Sexual Compulsivity Scales, Reliability, validity, and predicting HIV risk behavior. Journal of Personality Assessment, 65, 586-601. 
Kalichman, S. C. \& Cain, D. (2004). The relationship between indicators of sexual compulsivity and high risk sexual practices among men and women receiving services from a sexually transmitted infection clinic. Journal of Sex Research, 41, 235-241.

Kanuga, M., \& Rosenfeld, W. D. (2004). Adolescent sexuality and the Internet, The good, the bad, and the URL. Journal of Pediatric and Adolescent Gynecology, 17, 117-124.

Kaplan, H. S. (1996). Erotic obsession: Relationship to hypoactive sexual desire disorder and paraphilia. Americal Journal of Psychiatry, 153, 30-41.

Leiblum, S. R. (1997). Sex and the Net, Clinical implications. Journal of Sex Education and Therapy, 22, 21-27.

Malamuth, N. M., Addison, T. \& Koss, M. (2000). Pornography and sexual aggression, Are there reliable effects and can we understand them?, Annual Review of Sex Research, 11, 26-95.

Malamuth, N., \& Huppin, M. (2005). Pornography and teenagers: The importance of individual differences. Adolescent Medicine Clinics, 16, 315-326.

McNair, B. (2002). Striptease culture: Sex, media, and the democratization of desire. London: Routledge.

Miller, R. S., \& Lefcourt, H. M. (1982). The assessment of social intimacy. Journal of Personality Assessment, 46, 514-518.

Miner, M. H., Coleman, E., Center, B. A., Ross, M., \& Simon Rosser, B. R. (2006). The compulsive sexual behavior inventory, Psychometric properties. Archives of Sexual Behavior, 36, 579-587.

Parsons, J. T., Kelly, B. C., Bimbi, D. S., DiMaria, L., Weinberg, M. L., \& Morgenstern, J. (2007). Explanations for the origins of sexual compulsivity among gay and bisexual men. Archives of Sexual Behavior, Online First. 
Peter, J., \& Valkenburg, P. M. (2006). Adolescents' exposure to sexually explicit online material and recreational attitudes toward sex. Journal of Communication, 56, 639-660.

Salisbury, R. M. (2008). Out of control sexual behaviours: A developing practice model. Sexual and Relationship Therapy, 23, 131-139.

Schwartz, M., F. \& Southern, S. (2000). Compulsive cybersex, The new tea room. Sexual Addiction and Compulsivity, 7, 127-144.

Snell, W. E., Fisher, T. D. \& Walters, A. S. (1993). The multidimensional sexuality questionnaire, An objective self-reported measure of psychological tendencies associated with human sexuality, Annals of Sex Research, 6, 27-55.

Slaymaker, E. (2004). A critique of international indicators of sexual risk behaviour. Sexually Transmitted Infections, 80, 13-21.

Štulhofer, A., Urch, D., Marjanović, B., Bauer, M., Čupić, Z., Kunej, A., Mikac, U. et al. (2006). Spolne/rodne razlike u on-line seksualnim aktivnostima i njihovim posljedicama. /Gender differences in online sexual activities and their consequences./ Društvena istraživanja, 15, 1029-1045.

Štulhofer, A., Landripet, I., Matko, V., Kladarić, P. G. \& Buško, V. (2007). Pornography and sexual satisfaction. In: S. V. Knudsen, L. Lofgren-Martenson \& Mansson, S. A. (Eds.) Generation P? Youth, Gender and Pornography. Copenhagen: Danish University of Education Press.

Wallmyr, G., \& Welin, C. (2006). Young people, pornograpy, and sexuality, Sources and attitudes. Journal of School Nursing, 22, 290-295.

Watt, J. D., \& Ewing, J. E. (1996). Toward the development and validation of a measure of sexual boredom. Journal of Sex Research, 33, 57-66.

Wiederman, M. (1999). Volunteer bias in sexuality research using college student participants. Journal of Sex Research, 36, 59-66. 
Wellings, K., Collumbien, M., Slaymaker, E., Singh, S., Hodges, Z., Patel, D., \& Bajos, N. (2006). Sexual behaviour in context: a global perspective. Lancet, DOI:10.1016/S01406736(06)69479-8.

Wolak, J., Mitchell, K., \& Finkelhor, D. (2007). Unwanted and wanted exposure to online pornography in a national sample of young Internet users. Pediatrics, 119, 247-257.

Ybarra, M. L., \& Mitchell, K. J. (2005). Exposure to internet pornography among children and adolescents, A national survey. CyberPsychology and Behavior, 8, 473-486.

Zillmann, D. (2000). Influence of unrestrained access to erotica on adolescents' and young adults' dispositions toward sexuality. Journal of Adolescent Health, 27, 41-44. 
Table 1 - Sociodemographic and socio-sexual characteristics of the sample

\begin{tabular}{|c|c|c|c|c|}
\hline & & $\begin{array}{l}\text { Women } \\
(n=944)\end{array}$ & $\begin{array}{c}\text { Men } \\
(n=584)\end{array}$ & \\
\hline & & \multicolumn{2}{|c|}{$n(\%)$} & $p$ \\
\hline \multirow[t]{3}{*}{ Age } & & & & ns \\
\hline & $18-21$ & $386(40.9)$ & $234(40.1)$ & \\
\hline & $22-25$ & $558(59.1)$ & $350(59.9)$ & \\
\hline
\end{tabular}

Parents' education $\quad$ ns

Both parents without college education 412 (43.6) $229(39.2)$

One parent with college education $258(28.9) \quad 172(29.6)$

Both parents with college education $273(27.4) \quad 181(31.0)$

Place of residence at the age of 14

ns

$$
\begin{array}{rcc}
\text { Metropolitan setting } & 515(54.6) & 434(58.8) \\
\text { City } & 231(24.5) & 138(23.6) \\
\text { Town } & 124(13.1) & 69(11.8) \\
\text { Village } & 74(7.8) & 33(5.7)
\end{array}
$$

Currently in a relationship

$$
\begin{array}{lll}
\text { Yes } & 663(70.2) & 380(65.1) \\
\text { No } & 281(29.8) & 200(34.2)
\end{array}
$$

Age at first intercourse

$$
\begin{array}{rrr}
14 \text { or younger } & 20(2.1) & 28(4.8) \\
15 & 56(5.9) & 33(5.7) \\
16 & 148(15.7) & 83(14.2) \\
17 & 196(20.8) & 110(18.8)
\end{array}
$$


18 or older $524(55.5) \quad 330(56.5)$

Number of sexual partners (lifetime)

ns

$$
\begin{array}{rrr}
1 & 251(26.6) & 152(26.0) \\
2-3 & 313(33.2) & 176(31.1) \\
4-7 & 239(25.3) & 162(27.7) \\
8-11 & 91(9.6) & 55(9.4) \\
12 \text { or more } & 50(5.3) & 36(6.2)
\end{array}
$$

Age at first exposure to pornography

$$
\begin{array}{rrr}
10 \text { or younger } & 355(37.6) & 290(49.7) \\
11 & 84(8.9) & 64(11.0) \\
12 & 150(15.9) & 120(20.5) \\
13 & 143(15.1) & 61(10.4) \\
14 & 100(10.6) & 30(5.1) \\
15 \text { or older } & 103(10.9) & 18(3.1)
\end{array}
$$

Frequency of pornography use at 14

$$
\begin{array}{rcc}
\text { Every day } & 6(0.6) & 70(12.0) \\
\text { Several times a week } & 39(4.1) & 207(35.4) \\
\text { Several times a month } & 86(9.1) & 169(28.9) \\
\text { Once a month or less } & 280(29.7) & 105(18.0) \\
\text { Never } & 533(56.5) & 33(5.7)
\end{array}
$$

Sexual compulsivity

$$
\begin{array}{lll}
\text { High } & 133(14.1) & 177(30.3) \\
\text { Low } & 805(85.3) & 402(68.8)
\end{array}
$$


Table 2 - Associations between sexual risk taking, sexual intimacy, sexual contentment, and sexual compulsivity

\begin{tabular}{lcc}
\hline & Women & Men \\
\hline Condom used at last intercourse & $-.06(936)$ & $.01(577)$ \\
Condom consistency & $-.09^{* *}(936)$ & $-.01(578)$ \\
Number of sexual partners & $.12 * * *(939)$ & $.08^{*}(576)$ \\
\hline Intimacy & $-.22^{* * *}(933)$ & $-.23^{* * *}(573)$ \\
Partner communication & $-.07 *(920)$ & $-.04(564)$ \\
Relationship attitudes & $.26 * * *(928)$ & $.27 * * *(561)$ \\
\hline Sexual satisfaction & $-.21 * * *(937)$ & $-.22^{* * *}(573)$ \\
Sexual boredom & $.27 * * *(933)$ & $.37 * * *(573)$ \\
Anxiety and guilt felt after sex & $.17 * * *(937)$ & $.27 * * *(576)$ \\
\hline$* \mathrm{p}<.05 ; * \mathrm{p}<.01 ; * * * \mathrm{p}<.001$ & & \\
\hline
\end{tabular}


Table 3 - Differences in sexual risk taking, sexual intimacy, and sexual contentment between the participants scoring low and high in sexual compulsivity

\begin{tabular}{|c|c|c|}
\hline & Women & Men \\
\hline & \multicolumn{2}{|c|}{ Low vs. high SC group differences } \\
\hline & \multicolumn{2}{|l|}{$\chi^{2}$} \\
\hline Condom used at last intercourse & .00 & .23 \\
\hline Condom consistency & .01 & .29 \\
\hline \multirow[t]{2}{*}{ Number of sexual partners } & $11.64^{*}$ & 5.05 \\
\hline & \multicolumn{2}{|c|}{$t(d f)$} \\
\hline Intimacy & $1.72(932)$ & $2.22(371)^{*}$ \\
\hline Partner communication & $67(919)$ & $-.15(562)$ \\
\hline Relationship attitudes & $-3.65(163.38)^{* * *}$ & $-4.40(559)^{* * *}$ \\
\hline Sexual satisfaction & $3.25(936)^{* *}$ & $3.83(571)^{* * *}$ \\
\hline Sexual boredom & $-1.90(932)^{\mathrm{a}}$ & $-5.54(571)^{* * *}$ \\
\hline Anxiety and guilt felt after sex & $-2.41(936)^{*}$ & $-5.35(574)^{* * *}$ \\
\hline$* \mathrm{p}<.05 ; * * \mathrm{p}<.01 ; * * * \mathrm{p}<.00$ & & \\
\hline
\end{tabular}


Table 4 - Early exposure to pornography and frequency of use at 14 as correlates of high/low sexual compulsivity, controlled for age and pornographic genre

\begin{tabular}{rcc}
\hline & Women & Men \\
\cline { 2 - 3 }$(\mathrm{n}=886)$ & $(\mathrm{n}=558)$ \\
\cline { 2 - 3 }$(1=14$ or younger $)$ & $.57(.32-1.07)$ & $1.53(.39-5.91)$ \\
\cline { 2 - 3 } First exposure to pornography & & \\
Pornography use at 14 & & \\
Daily to several times a week & $2.14(.97-4.70)$ & $1.33(.51-3.44)$ \\
Several times a month & $.95(.47-1.93)$ & $1.49(.56-3.91)$ \\
Once a month or less & $1.04(.65-1.65)$ & $.62(.22-1.76)$ \\
Never (reference category) & 1 & 1 \\
\hline
\end{tabular}

